\title{
PESQUISA EDUCACIONAL: DESAFIOS E POSSIBILIDADES
}

\author{
RIBEIRO, Alcides Mariano ${ }^{1}$ \\ BUENO, José Lucas Pedreira ${ }^{2}$ \\ ISOBE, Rogéria Moreira Rezende ${ }^{3}$
}

\begin{abstract}
Recebido em: 2020.07 .23
Aprovado em: 2020.10 .19

ISSUE DOI: $10.3738 / 1982.2278 .3823$

RESUMO: O objetivo do estudo é analisar o desenvolvimento da pesquisa em Educação no Brasil. Quais problemas teórico/metodológicos limitam o trabalho dos pesquisadores? Este trabalho é fruto de reflexões e estudos realizados no Programa de Pós-Graduação em Educação da Universidade Federal do Triângulo Mineiro (UFTM). Procura-se caracterizar, por meio de levantamento bibliográfico, reflexões ao atual cenário das pesquisas qualitativas, apresentar o contexto educacional contemporâneo no país, bem como seus obstáculos. Explicita-se a transição do saber espontâneo ao racional, apresentando as diferenças entre método científico nas Ciências Naturais e Humanas. É traçado quadro histórico do processo de maturação da pesquisa em educação, as questões metodológicas, desafios e relevância da pesquisa para o avanço do conhecimento na área. Defende-se a ideia de que a adequada pesquisa qualitativa pode apontar caminhos para aprimorar a educação brasileira.
\end{abstract}

Palavras chave: Pesquisa Qualitativa. Educação no Brasil. Ciências Humanas.

\section{EDUCATIONAL RESEARCH: CHALLENGES AND POSSIBILITIES}

\begin{abstract}
SUMMARY: The objective of the study is to analyze the development of research in Education in Brazil. What theoretical / methodological problems limit the work of researchers ?. This work is the result of reflections and studies carried out in the Graduate Program in Education at the Federal University of Triângulo Mineiro (UFTM). It seeks to characterize, by means of bibliographic survey, the current scenario of qualitative research, to present the contemporary educational context in the country, as well as its obstacles. The transition from spontaneous to rational knowledge is explained, showing the differences between scientific method in Natural and Human Sciences. A historical picture of the maturation process of research in education is outlined, the methodological issues, challenges and relevance of research for the advancement of knowledge in the area. The idea is defended that adequate qualitative research can point out ways to improve Brazilian education.
\end{abstract}

Keywords: Qualitative Research. Education in Brazil. Human Sciences.

\section{INVESTIGACIÓN EDUCATIVA: RETOS Y POSIBILIDADES}

RESUMEN: El objetivo del estudio es analizar el desarrollo de la investigación en Educación en Brasil. ¿Qué problemas teórico / metodológicos limitan el trabajo de los investigadores ?. Este trabajo es el resultado de reflexiones y estudios realizados en el Programa de Posgrado en Educación de la Universidad Federal del Triângulo Mineiro (UFTM). Se busca caracterizar, mediante levantamiento bibliográfico, reflexiones sobre el escenario actual de la investigación cualitativa, para presentar el contexto educativo contemporáneo en el país, así como sus obstáculos. Se explica la transición del conocimiento espontáneo al racional, mostrando las diferencias entre el método científico en las Ciencias Naturales y Humanas. Se esboza un cuadro histórico del proceso de maduración de la investigación en educación, los aspectos

\footnotetext{
${ }^{1}$ Mestrando em Educação na Universidade Federal do Triângulo Mineiro (UFTM). Especialista em metodologia Ensino de História e Geografia. Especialista em Gestão Educacional: Orientação e Supervisão. Currículo Lattes $\mathrm{n}^{\circ}$ 2199932818322128. E-Mail: alcidesmribeiro@hotmail.com.

${ }^{2}$ Professor Doutor do Programa de Pós-Graduação em Educação (PPGE) da Universidade Federal do Triângulo Mineiro (UFTM). Coordenador do Departamento de Educação da Universidade Federal do Triângulo Mineiro (UFTM). Professor do Programa de Pós-Graduação em Educação Escolar da UNIR - Mestrado e Doutorado Profissional. Currículo Lattes $\mathrm{n}^{\circ}$ 0805268924348920. E-Mail: lucas.bueno@uftm.edu.br.

${ }^{3}$ Professora do Departamento de Educação da Universidade Federal do Triângulo Mineiro. Doutora em Educação pela Pontifícia Universidade Católica de São Paulo. Currículo Lattes n 5970509404713363. E-Mail: rogeriaisobe@gmail.com.
} 
metodológicos, desafíos y relevancia de la investigación para el avance del conocimiento en el área. Se defiende la idea de que una investigación cualitativa adecuada puede señalar formas de mejorar la educación brasileña.

Palabras clave: Investigación cualitativa. Educación en Brasil. Ciencias Humanas.

\section{INTRODUÇÃO}

Este trabalho procura caracterizar, por meio do levantamento bibliográfico, o atual cenário da pesquisa em Educação no Brasil, edificado ao longo da segunda metade do século XX e início do XXI. Será apresentado o contexto educacional contemporâneo no Brasil, bem como os obstáculos encontrados para a concretização de uma educação pública, gratuita e laica (e para todos) ${ }^{4}$. Para melhor compreensão desse contexto, será tratada aqui a transição do saber espontâneo para o racional, apresentando as diferenças entre "método" nas ciências naturais e humanas. Para contextualização histórica, será traçado quadro do desenvolvimento das pesquisas em Educação no país, as questões metodológicas, suas problemáticas e relevância para o avanço científico na área.

Acredita-se que o presente texto contribui para ampliar a compreensão do campo da Educação no Brasil e das características da abordagem qualitativa. Este trabalho é fruto de reflexões e estudos realizados no Programa de Pós-Graduação em Educação da Universidade Federal do Triângulo Mineiro (UFTM).

Para Pedro Demo (2011), toda pesquisa deve ser comunicada, ela é condição essencial do descobrir e criar. Quem investiga tem o que indagar e comunicar. Neste sentido, levantamos a seguinte questão: em que medida o desenvolvimento da pesquisa em Educação no Brasil é caracterizado? Quais os principais problemas teóricos-metodológicos os pesquisadores evidenciam?

O procedimento técnico-metodológico empregado é a investigação bibliográfica, discutida no grupo de estudos realizado no Programa de Pós-Graduação em Educação (PPGE) da Universidade Federal do Triângulo Mineiro (UFTM). Os referenciais teóricos explorados possibilitaram-nos clareza e aprofundamento nas discussões, previamente indagadas no PPGE, organizando assim as ideias de forma sistemática para responder teoricamente o problema levantado. Para discutir e refletir sobre o campo da pesquisa em educação, contamos com as contribuições de Gatti (2012; 2007; 2001); Gatti e André (2010); André (2010); Demo (2011); Alves-Mazzotti e Gewandsznajder (1999); Saviani (2011; 2004) Severino (2002); Laville e Dionne (1999); e Oliveira (1998) como referencial. A pesquisa se situa nas dimensões: teórico-metodológico, técnico-metodológico e político-educacional.

\footnotetext{
${ }^{4}$ Ideias aspiradas desde o início do século XX, com a publicação do "Manifesto dos Pioneiros da Educação Nova" em 1932. Embora o documento tenha tido como signatários 26 grandes educadores do período, os ideais defendidos ainda não foram concretizados nove décadas após a sua publicação.
} 
Quadro 1: Referencial teórico principal e sua relevância.

\begin{tabular}{|c|c|c|c|c|}
\hline Referencial teórico & $\begin{array}{ll}\text { Título } & \text { do } \\
\text { trabalho } & \end{array}$ & Ano & Tipo & Relevância \\
\hline $\begin{array}{c}\text { GATTI, Bernadete } \\
\text { Angelina }\end{array}$ & $\begin{array}{lr}\text { A } & \text { construção } \\
\text { metodológica } & \text { da } \\
\text { pesquisa } & \text { em } \\
\text { educação: } & \\
\text { desafios. } & \end{array}$ & 2012 & Artigo & Citado 94 vezes \\
\hline $\begin{array}{l}\text { GATTI, Bernadete; } \\
\text { ANDRÉ, Marli. }\end{array}$ & $\begin{array}{lr}\text { A relevância } & \text { dos } \\
\text { métodos } & \text { de } \\
\text { pesquisa } & \\
\text { qualitativa } & \text { em } \\
\text { Educação } & \text { no } \\
\text { Brasil. } & \end{array}$ & 2010 & Artigo & Citado 206 vezes \\
\hline $\begin{array}{c}\text { GATTI, Bernadete } \\
\text { Angelina }\end{array}$ & $\begin{array}{lr}\text { A construção } & \text { da } \\
\text { pesquisa } & \text { em } \\
\text { Educação } & \text { no } \\
\text { Brasil } & \end{array}$ & 2007 & Livro & Citado 992 vezes \\
\hline $\begin{array}{c}\text { GATTI, Bernadete } \\
\text { Angelina }\end{array}$ & $\begin{array}{lr}\text { Implicações } & \text { e } \\
\text { perspectivas } & \text { da } \\
\text { pesquisa } & \\
\text { educacional no } & \text { no } \\
\text { Brasil } & \\
\text { contemporâneo } & \end{array}$ & 2001 & Artigo & Citado 284 vezes \\
\hline
\end{tabular}

Fonte: Google Acadêmico (agosto de 2020)

Como podemos notar, selecionamos os principais trabalhos (acima de 50 citações) relacionados ao tema nos últimos 19 anos de Bernadete Angelina Gatti, pesquisadora sênior da Fundação Carlos Chagas, uma das principais especialistas em pesquisa educacional do Brasil. A pesquisa foi realizada na plataforma de busca do Google Acadêmico, incluímos todos os títulos relacionados ao tema (Busca: Gatti+Pesquisa+Educação). Excluímos os demais trabalhos que não se relacionavam aos desafios e as possibilidades da pesquisa educacional no Brasil. Os demais teóricos citados neste relatório foram de suma importância ao aporte teórico e construtivo da presente investigação.

O trabalho está estruturado em três partes, na primeira parte do estudo, "Reflexões sobre atual panorama educacional do Brasil”, procuramos apresentar os dados atuais sobre a alfabetização, ensino e concentração de renda no Brasil; em "Saberes, ciência positivista, ciências humanas: a pesquisa e o pesquisador", tecemos considerações sobre a transição do saber espontâneo para o racional e a distinção quantitativa-qualitativa; em “A pesquisa em Educação no Brasil: apontamentos”, procuramos traçar historicamente a expansão das investigações sobre educação no Brasil, as questões de método e suas problemáticas; e, finalmente, em "Considerações Finais", concluímos a necessidade de um desenvolvimento teórico-metodológico consistente nos trabalhos acadêmicos, contribuindo para superar as barreiras dos estudos estabelecidos, respondendo aos anseios sociais à educação pública, gratuita e laica. 


\section{REFLEXÕES SOBRE O ATUAL PANORAMA EDUCACIONAL DO BRASIL}

Ter as portas abertas da "Universidade Federal" é fundamental para que pesquisadores possam dar continuidade às pesquisas na área de Ciências Humanas, em especial na da Educação. Esse processo testemunha que o projeto educacional dos anos 1930 em prol da instrução pública, gratuita e laica enfrenta ainda obstáculos colocados pelo sistema capitalista. Esses ideais alvoreceram durante a primeira metade do século XX. Segundo Saviani (2004) o Manifesto dos Pioneiros da Educação Nova, criado em 1932, preconizava efetuar a reconstrução social pela via educacional. Contudo, o processo histórico demonstra que não conseguimos resolver as contradições socioeconômicas e concretizar esse ideal no nosso país.

A educação institucional no Brasil, fruto das políticas governamentais, não atingiu no século XXI as aspirações defendidas no século precedente - a democratização do ensino gratuito e de qualidade para todos. Esta problemática reflete a incapacidade e desinteresse do Estado em organizar e implementar uma política educacional abrangente e digna para seus cidadãos. Nesta perspectiva, Almeida (2004) expressa:

O projeto pedagógico que deveria ser o sonho possível se mantém nos mesmos patamares dos últimos duzentos anos, revelando a crise do Estado e seu desinteresse pelas prioridades sociais, mesmo com as resistências que, por sua vez, ecoam afônicas perante a avalanche do lucro fácil e a desvalorização da vida humana (ALMEIDA, 2004, p. 3).

Neste sentido, mesmo com a tradição brasileira de educação dual ${ }^{5}$, ou seja, sistemas diferentes de ensino: um para o pobre (transformação das classes indolentes em operários úteis) e outro para o rico (formando as elites que conduziriam o destino do país), vemos que avançamos a passos lentos para mudar os rumos das raízes educacionais do Brasil que, tradicionalmente, caminhou e caminha para atender as demandas do setor produtivo, sem a preocupação em universalizar o ensino de qualidade para todos (AZEVEDO, 2009).

Vivemos períodos de incertezas e mudanças drásticas, típicas do pós-modernismo. Algumas características marcantes destes tempos pós-modernos ${ }^{6}$ é a fragmentação, a sociedade de consumo (consumismo personalizado), a moral hedonista, o niilismo, o narcisismo, a melancolia, o hiperrealismo, o simulacro, o espetacularismo e a desreferenciação do ensino (SANTOS, 2006).

Dentro desta lógica de desconstrução dos grandes paradigmas de explicação da realidade, encontra-se uma grande crise na ciência em geral e descrença nos preceitos fundadores da sociedade moderna - as instituições, como a escola. Nesta era do capitalismo neoliberal globalizado e descrente, a coletividade desvaloriza a cultura elevada pelo cotidiano banalizado, renuncia à arte pela antiarte,

\footnotetext{
${ }^{5}$ A expressão "educação dual” foi retirada das considerações de Azevedo (2001).

6 "Pós-modernismo é o nome aplicado às mudanças ocorridas nas ciências, nas artes e nas sociedades avançadas desde 1950, quando, por convenção, se encerra o modernismo (1900-1950)”. (SANTOS, 2006, p. 7-8).
}

Nucleus, v.17, n.2, out. 2020 
esvazia a estética e prioriza a desestetização de tudo, prefere a apresentação à interpretação. Vivemos tempos de incertezas e de crises estruturais, nos valores e na educação (SANTOS, 2006).

A educação brasileira neste contexto está entregue aos reformadores empresariais e ao neotecnicismo - típicos da atual sociedade capitalista. Ocorre mercantilização das escolas e consequentemente do conhecimento. Os educandos são tratados como clientes e os pais, na qualidade de consumidores, apontam alguns aspectos dos tempos atuais no nosso país (GOODSON, 2008). Para Akkari (2011), o Estado atribui a si mesmo um novo papel "regulador e avaliador que define as grandes orientações e metas a atingir e coloca em prática um sistema de monitoramento e avaliação do cumprimento dos resultados desejados" (p. 18). Regular e avaliar o setor educacional demonstra claramente a tendência neoliberal de desobrigação do Estado com a educação.

Em muitos estados brasileiros já foi implantada a mencionada política meritocrática, empresarial e técnica. O sistema governamental nivela o ensino ao básico, privilegiando disciplinas como Língua Portuguesa e Matemática. Neste sentido, excluem e sonegam aos educandos o que é "irrelevante" aos olhos da ideologia governamental orientada que se encontra no poder. Para Freitas (2011), as habilidades afetivas, sentimentais e as artes são excluídas indiretamente, em nome de um treinamento técnico para ser aprovado em um determinado sistema avaliativo. Neste sentido, a escola forma cidadãos de segunda categoria, para serem trabalhadores técnicos, servindo aos interesses da elite.

O trabalho docente se submete a determinada alienação imposta. Fica evidente a angústia dos professores diante deste sistema de políticas de padronização e mensuração do exercício discente nas escolas. As prescrições os impedem de desenvolver um ofício humanizador, em favor do aluno e da sua aprendizagem (NACARATO, 2016). Este modelo se originou nos Estados Unidos ${ }^{7}$ e foi implementado pelo MEC em nosso país. Delega a responsabilização da educação aos empresários e aos municípios, acentuando as desigualdades educacionais, refletindo no seio social e resultando no fracasso escolar (SAVIANI, 2004).

O Estado se mantém omisso em relação aos dilemas sociais mais relevantes (educação, saúde, segurança), suas medidas são superficiais para efeitos breves em curto prazo. Não criam soluções que transformem a realidade estrutural dos problemas históricos que afligem a sociedade brasileira, o que evidencia desinteresse pelas classes desfavorecidas socialmente. A história demonstra que o Estado valoriza os interesses econômicos dos grandes capitais e menospreza a "vida humana", num processo de desumanização e hipercapitalização, ampliando os abismos sociais (SHIROMA; MORAES; EVANGELISTA, 2002).

\footnotetext{
${ }^{7}$ Para Saviani (2004), o modelo neoliberal, educação por resultados, foi um fracasso no seu país de origem Estados Unidos, na Europa Ocidental e também no Brasil.
} 
O Relatório de Desenvolvimento Humano $(\mathrm{RDH})^{8}$ da Organização das Nações Unidas (ONU), divulgado dia 09 de dezembro de 2019, aponta o Brasil como o segundo pior país no índice de distribuição de renda no mundo. O documento foi organizado pelo Programa das Nações Unidas para o Desenvolvimento (PNUD). Os $1 \%$ mais endinheirados da nação concentram assustadoramente 28,3\% de toda riqueza produzida. Ao comparar os $10 \%$ mais ricos, o número é alarmante, concentrando 41,9\% do total da riqueza do país.

Ao comparar o Brasil com os países que fazem parte das economias emergentes (BRICS) ${ }^{9}$, o relatório aponta que nossa nação possui a maior concentração de renda de todos do grupo em desenvolvimento. Estes dados demonstram as fragilidades históricas que temos em termos de distribuição de riquezas, concentrando-a nas mãos de poucos e destituindo os pobres, impedindo-os de ter uma melhor participação na riqueza econômica nacional.

O PNUD também aponta que o Índice de Desenvolvimento Humano do país teve uma irrisória melhoria de 0,001 em relação ao ano anterior, em 2017 foi de 0,760 e em 2018, de 0,761. Exemplo claro é a queda do Brasil no ranking mundial, caindo da $78^{\mathrm{a}}$ para a $79^{\mathrm{a}}$ posição. O Brasil aparece na quarta colocação da América do Sul, empatado com a Colômbia. Entretanto, se for considerada a riqueza produzida, nosso país deveria liderar. Vemos que os números econômicos não se traduzem efetivamente em melhorias significativas nas áreas de saúde, educação e renda, dados base para a estipulação do IDH.

A concentração de renda nas mãos de poucos acarreta o crescimento das desigualdades sociais. A riqueza produzida no mundo do trabalho é uma realidade, mas ela está sendo "mal” distribuída no país, com números preocupantes, como foi apresentado acima. São necessárias políticas públicas que sejam sérias e sólidas para combater as graves consequências que a desigualdade produz e reproduz. A educação precisa ser a área que o governo deve priorizar, proporcionando acesso igualitário e de qualidade para crianças e jovens às escolas públicas.

A escola (instituição de ensino por excelência) não atingiu um patamar elevado de auxílio cultural para a ascensão das camadas de baixa renda - Educação Básica e Ensino Superior. As diferenças econômicas e sociais continuam se avolumando. Segundo a Pesquisa Nacional por Amostra de Domicílios (PNAD/IBGE) de 2017, a taxa de analfabetismo no Brasil entre pessoas de 15 anos ou mais de idade, está em 7\% (11,5 milhões de analfabetos). Também 7,3 milhões de crianças entre 0 a 5 anos não frequentara a escola.

Estima-se que 196 mil crianças entre 4 e 5 anos não frequentam a escola por falta de vaga ou por falta da instituição na localidade de moradia. A taxa de pessoas de 25 anos ou mais que não

\footnotetext{
${ }^{8}$ O relatório analisa todos os países do mundo com dados disponíveis na ONU no período de 2010 a 2017.

${ }^{9}$ BRICS designa o grupo de países emergentes que incluem Brasil, Rússia, Índia, China e África do Sul.

Nucleus, v.17, n.2, out. 2020
} 
completaram o Ensino Fundamental é de 33, 8\%. E somente 46,1\% da população de 25 anos ou mais concluíram a Educação Básica. A taxa de escolarização entre pessoas de 18 a 24 anos caiu de 32,8\% em 2016 para 31,7\% em 2017. Números alarmantes que refletem os problemas educacionais que o país enfrenta.

Percebemos que nas últimas décadas, vivemos momentos de avanços e retrocessos. Dados apresentados pelo Programa Internacional de Avaliação de Estudantes (PISA), elaborado pela Organização para Cooperação e Desenvolvimento Econômico (OCDE) a cada triênio, apontam um processo de estagnação no aprendizado básico dos jovens e adolescentes. Os dados foram divulgados no dia 03 de dezembro de 2019, quando foi constatado que $43 \%$ dos alunos entre 15 e 16 anos não possuem aprendizagem básica para a faixa etária, nos conhecimentos de leitura, ciências e matemática.

O país avançou nos índices educacionais entre os anos de 2000 a 2009 e na última década (2010-2020) vem intercalando avanços e retrocessos no desempenho educacional, ficando entre os piores índices dos países participantes da avaliação do Pisa. Maiores investimentos em pesquisas educacionais são imprescindíveis para responder aos desafios apresentados e superar as barreiras do estabelecido, respondendo aos anseios sociais com instrução de qualidade, distribuição de renda, erradicação do analfabetismo e melhores desempenhos educativos em nível mundial.

Para Almeida (2004, p. 8) "somos herdeiros de um século que ao findar ainda não resolveu suas contradições, nas quais se inclui a educação como direito de todos”. Neste contexto, de descrença, incertezas e desobrigação do Estado, acreditamos no poder transformador da sociedade por meio da Educação. Neste sentido, as pesquisas educacionais, com suas ferramentas epistemológicas tornam-se imprescindíveis como caminho explicativo da anomalia social. A continuidade das investigações na área das Ciências Humanas demonstra que o projeto educacional dos anos 1930 em prol de uma educação pública, gratuita e laica demanda vencer os obstáculos colocados pelo sistema capitalista.

\section{SABERES, CIÊNCIA POSITIVISTA, CIÊNCIAS HUMANAS: A PESQUISA E O PESQUISADOR.}

Diante dos dados apresentados, iremos abordar, por meio da historicidade, os diversos conhecimentos apreendidos pelo homem, demonstrar como foram elaborados e evoluíram; Aprofundar a discussão sobre conhecimento e pesquisa, demonstrando a transição do saber espontâneo para o racional; Apresentar as diferenças entre: método científico das ciências naturais e humanas, para atingirmos os objetivos propostos neste trabalho.

A necessidade de sobrevivência levou o homem a buscar conhecimento. Inicialmente estava centrado nos "Saberes Espontâneos" (pré-histórico/primeiras civilizações), ou seja, conhecimento 
adquirido pela experiência. Conhecer para controlar, utilizando a intuição, a observação e o mito ${ }^{10}$ para explicar os fenômenos não conhecidos.

Os "Saberes Espontâneos" foram forjados e legitimados na intuição e perpetuados pela tradição. Validados como saberes úteis, legados do passado para ditar regras e comportamentos. Para Laville e Dionne (1999), o saber tradicional era transmitido pela figura da autoridade ${ }^{11}$, perpetuando princípios sem provas metodicamente elaboradas. A sabedoria das autoridades neste contexto é permeada de espontaneidade, típica do senso comum. Estes saberes produzem conhecimentos simples e cômodos para a sociedade, adquiridos por meio da observação imediata.

O saber científico surgiu da fragilidade da intuição do senso comum na busca de conhecimentos mais confiáveis. Para Demo (2011), a diferença entre este modelo de outros saberes é o método. Laville e Dionne (1999) reconstroem o desenvolvimento do conhecimento racional ao longo da história, demonstrando as contribuições no transcurso do tempo para a construção do conhecimento científicometodológico. Analisam esse processo a partir das civilizações clássicas (greco-romana) até o nascimento das ciências humanas no século XX.

Os gregos possivelmente foram os primeiros a desconfiar do mito/senso comum. Desenvolveram o raciocínio indutivo e juntamente com o dedutivo, foram fundamentais para a construção metódica do saber. Laville e Dionne (1999) salientam que cientificismo neste contexto histórico se confundia com o saber filosófico. Os pensadores romanos contribuíram com a técnica. Os filósofos da Igreja na Idade Média colaboraram com a Teologia. Estes subsídios ao longo dos séculos foram essenciais para o nascimento do método científico. Nada se cria ao acaso, tudo que existe possui antecedentes históricos (DEMO, 2011).

No século XVII, ocorre a gênese do pensamento científico moderno, o empirismo ${ }^{12}$. Método experimental baseado na observação, experimentação e mensuração, buscando encontrar explicações gerais e definir o princípio que fundamenta tais diretrizes. No século XVIII, ocorre o florescimento da ciência empírica, com novas descobertas no campo da natureza física e social, principalmente com o auxílio da filosofia iluminista, que marcou profundamente essa época denominada "período das luzes". 13

No século XIX, ocorre o triunfo da ciência, com aplicações práticas. A partir da pesquisa racionalista e aplicada, o progresso científico possibilitou o aperfeiçoamento material em diversas

\footnotetext{
${ }^{10}$ Para Silva e Silva (2005, p. 294) os antropólogos definem o conceito de mito como "uma narrativa, uma reflexão alegórica sobre a existência, e carrega uma mensagem implícita capaz de revelar o pensamento de uma sociedade".

${ }^{11}$ Chefes de famílias (ou clãs), lideres religiosos como sacerdotes, pajés e clérigos.

${ }^{12}$ Sem desconsiderar as contribuições da antiguidade clássica, estamos nos referindo ao método científico baseado em experiências, com as contribuições de Francis Bacon, John Locke, entre outros.

${ }^{13}$ Termo empregado para conceituar os filósofos iluministas, que orientavam suas reflexões ao pensamento racional e a fé nos poderes da razão para orientar as ações humanas, entre eles podemos citar Voltaire, Rousseau, Montesquieu, entre outros.
} 
áreas, como: agricultura, manufatura, fontes de energia, transportes, comunicação, saúde e urbanização. $\mathrm{O}$ aprimoramento técnico gerou diversos problemas sociais ${ }^{14}$. Para conhecer e interpretar tais patologias ocorreu o surgimento das ciências humanas com o positivismo ${ }^{15}$ (física social).

O positivismo utilizou o método aplicado nas ciências naturais para interpretar a sociedade. Para os positivistas, os fatos humanos eram causais, suscetíveis à experimentação para determinar suas causas e explicações gerais. Consideravam o organismo social em termos de causa e efeito, interpretando o homem de modo objetivo e quantitativo.

Mas, no século XX, o paradigma positivista foi questionado, cedendo espaço para a subjetividade nas interpretações das questões sociais. Os fatos naturais possuem explicação causal objetiva. As relações humanas são complexas e de explicações subjetivas, ou seja, os seres humanos apresentam reações diferentes sobre o mesmo fato. O positivismo se tornou impróprio como modelo explicativo das humanidades. As generalizações e objetividade das ciências naturais não se aplicam ao organismo social (LAVILLE E DIONNE, 1999). Seguem abaixo as características do positivismo, que durante muito tempo se fizeram presentes nas Ciências Humanas, a saber:

\section{Quadro 2: As características do positivismo.}

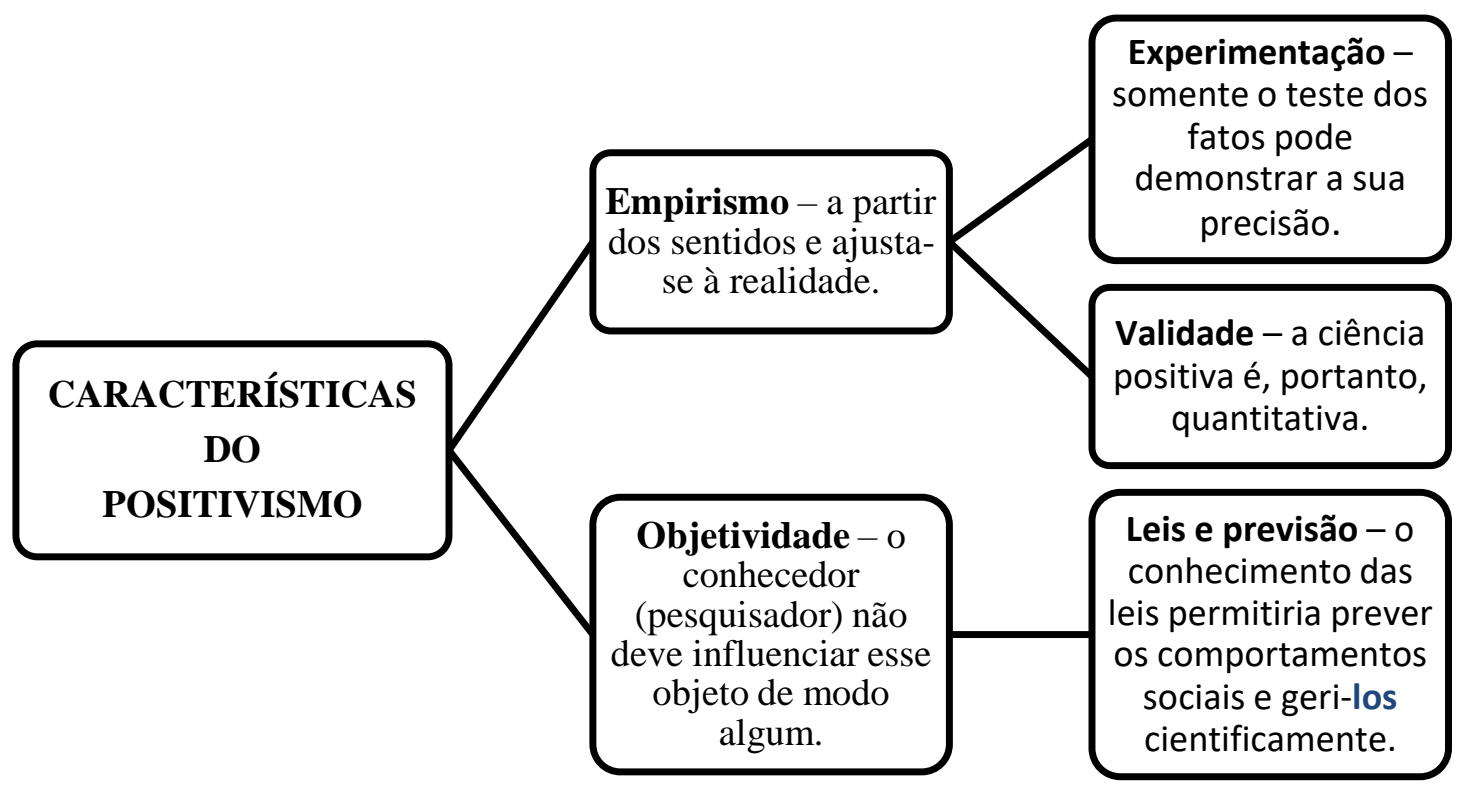

(Baseado em LAVILLE E DIONNE, 1999).

O conhecimento objetivo (positivismo) cedeu lugar à teoria transitória. A objetividade positiva converte-se na subjetividade qualitativa. Para Laville e Dionne (1999), as compreensões das ciências humanas são relativas. As análises sociais atualmente não são quantitativas, mas, qualitativas, buscando conhecer as motivações, as representações e os valores, traçando o real a seu modo. A pesquisa atual

\footnotetext{
${ }^{14}$ Como problemas sociais desse período, podemos citar as novas relações de trabalho, o êxodo rural, crescimento urbano, marginalização, alcoolismo, fome, miséria, desemprego, prostituição, greves e manifestações.

${ }^{15}$ Corrente filosófica baseada nas ideias de Auguste Comte (1798-1857), chamada de "Física social", com o objetivo de interpretar as anomalias pelas quais a sociedade industrial passava. Comte é considerado o pai da sociologia.
} 
possui três grandes características: visão holística, abordagem indutiva e investigação naturalística (ALVES-MAZZOTTI E GEWANDSZNAJDER, 1999).

O método científico nas ciências humanas parte de uma problematização, formulando-a em pergunta. Posteriormente elabora-se uma hipótese, consciente de sua transitoriedade e implicações lógicas, verifica-a, analisando, avaliando e interpretando os dados. Por fim, conclui, invalidando ou confirmando a tese, traçando uma explicação significativa e, quando possível, generalizando. O pesquisador objetiva o subjetivo em teoria (DEMO, 2011; GATTI e ANDRÉ, 2010).

A principal problemática que surgiu foi a divisão disciplinar como um obstáculo a compreensão global de um determinado problema. Como solução a esta questão, ocorreu o nascimento da abordagem multidisciplinar $^{16}$, utilizando diversas disciplinas auxiliares para interpretar os problemas sociais. A pesquisa multidisciplinar é a notável característica das ciências humanas atualmente, utilizando-se do método problematizador ${ }^{17}$. "Para descobrir e criar é preciso primeiro questionar" (DEMO, 2011, p. 35).

Seguem abaixo as características da pesquisa em Ciências Humanas atualmente:

\section{Quadro 3: As características da pesquisa em Ciências Humanas.}

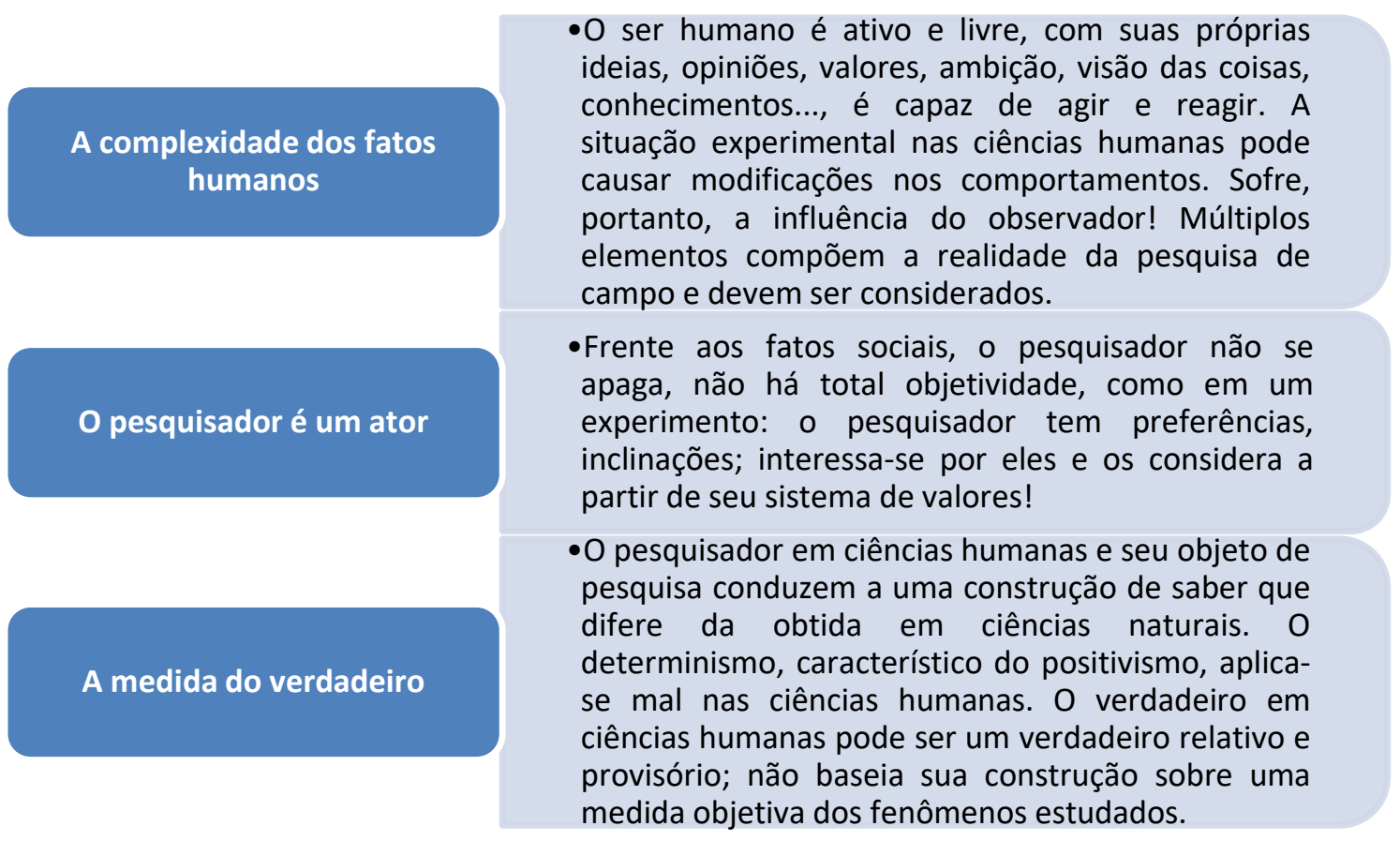

(Baseado em LAVILLE E DIONNE, 1999).

\footnotetext{
${ }^{16}$ Para Alves-Mazzotti e Gewandsznajder (1999) a pesquisa em educação é qualitativa, possui uma natureza interdisciplinar, congregando diversas áreas das ciências sociais.

17 "A fecundidade de uma pergunta é a garantia de que a resposta à mesma significará um esclarecimento e muitas outras dúvidas" (MACHADO, 2004, p. 15).
}

Nucleus, v.17, n.2, out. 2020 
O pesquisador ${ }^{18}$ é um agente histórico e social da pesquisa, com suas ideias, indagações e anseios. Para Demo (2011) o investigador é um ator e ao mesmo tempo, um fenômeno político. Ele nunca é neutro, mobilizando seus conhecimentos para reconstruir a realidade conforme seus interesses e esperanças. Para Gatti (2012), ele procura demonstrar em sua investigação interpretações plausíveis sobre determinado fato em estudo. A verdade é provisória (uma possibilidade), uma construção relativa, política, permeada pelas inclinações do pesquisador (DESLANDES, 2004) ${ }^{19}$.

Assim, procuramos fundamentar a construção do conhecimento pelo homem, distinguindo saber científico e saber comum, bem como a importância da razão e do método e o nascimento da experimentação como base para o desenvolvimento da ciência moderna. No século XIX verificaram-se os resultados práticos do triunfo científico ao lado dos problemas gerados pela racionalidade técnicocientífica.

Buscamos compreender como as ciências humanas se constituíram enquanto método de explicação dos problemas sociais. As diferenças entre o campo natural e humano. A objetividade dos fatos naturais e a complexidade da subjetividade humana. Por fim, caracterizamos a dicotomia entre a generalização imutável das ciências naturais e a transitoriedade das ciências humanas, e o papel político e existencial do pesquisador ${ }^{20}$. Estas reflexões ampliam o horizonte do investigador sobre a importância do conhecimento em sua constituição histórica e enquanto método de aplicação na compreensão da realidade social (GATTI e ANDRÉ, 2010).

\section{PESQUISA EDUCACIONAL: DESAFIOS E POSSIBILIDADES}

Para traçar historicamente o desenvolvimento da pesquisa em Educação no Brasil, as questões de método, suas problemáticas e as investigações que vem sendo publicadas em revistas científicas a partir da década de 1970, contamos como referencial teórico com as contribuições de Gatti (2012; 2010; 2007; 2001), Gatti e André (2010) e o aporte de: André (2010); Demo (2011); Alves-Mazzotti e Gewandsznajder (1999); Saviani (2011; 2004); Severino (2002); e Oliveira (1998), que nos possibilitam refletir e discutir sobre o campo da pesquisa educacional ${ }^{21}$.

Inicialmente, procuramos caracterizar o desenvolvimento das pesquisas em educação. Por meio de um levantamento histórico, é possível perceber o progresso iniciando na década de 1960 e ampliando nas décadas de 1970/80. Passando por estágios de ampliação, de organização e maturação. Gatti (2007; 2001) não deixa de analisar criticamente as contribuições deste período, bem como os

\footnotetext{
${ }^{18}$ Para Demo (2011) o pesquisador não pode desistir de questionar a realidade. O questionamento precisa corresponder aos anseios sociais.

${ }^{19}$ Para Demo (2011) a ciência tem sempre a marca do seu construtor.

${ }^{20}$ Para Severino (2002) a produção científica se viabiliza e justifica por meio da ligação (vínculo) entre a pesquisa e o projeto político e existencial do pesquisador.

${ }^{21}$ Campo educacional se refere às investigações relativas a área da Educação, interiorizadas na área das Ciências Humanas, com interfaces em outras disciplinas como a psicologia, história, biologia, filosofia, sociologia, antropologia e ciência política.
} 
contrapontos e desafios que nasceram e os muitos que permanecem atualmente na área da pesquisa educacional.

O início da pós-graduação ocorreu nos anos 1960, com a ampliação e aceleração das pesquisas no Brasil. Na década de 1970, veio a expansão das temáticas educacionais e o aprimoramento metodológico. Nos anos 1980/90, principia o nascimento de novas metodologias ${ }^{22}$, como, a pesquisaação e teorias do conflito e a gênese dos grupos de estudo em educação, dentro das universidades. A consolidação destes grupos ocorre mediante o respaldo da Associação Nacional de Pós-Graduação e Pesquisa em Educação (ANPED), fundada em 1978, e, a partir de 1980, vem contribuindo para o desenvolvimento da área (SAVIANI, 2011; GATTI, 2007; 2001).

Os primeiros programas de pós-graduação dos anos 1970 tiveram como influência a "orientação tecnicista". Saviani (2011) ressalta a prevalência de concepções extrangeiras, principalmente a norteamericana na "estrutura organizacional". O autor não deixa de expor que o espírito dos programas foram inspirados pela experiência universitária da Europa continental. Essa discrepância entre estrutura técnica e concepção teórica divergente ocorreu porque a maior parte dos docentes de pós-gradução vinham de uma formação acadêmica inspirada pela influência europeia (SAVIANI, 2011).

O professor Saviani (2011) explica claramente, na citação abaixo esta discrepância que de certamente induziu a pós-graduação entre tecnicismo americado e teoricismo europeu:

Ora, enquanto a experiência universitária norte-americana põe certa ênfase no aspecto técnicooperativo, na experiência europeia a ênfase principal recai sobre o aspecto teórico. Fundindo a estrutura organizacional do modelo americano com a densidade teórica resultante da influência europeia, a pós-graduação brasileira acabou por produzir um modelo novo, decerto superior àqueles que lhe deram origem. (Saviani 2011, p. 392-393)

Vemos por meio da citação acima que a influência europeia na formação dos docentes a frente da pós-graduação contribuiu como um contraponto a hegemonia norte-americana ao ensino superior brasileiro a partir da Reforma Universitária (Lei n 4024 de 1968). Para Saviani (2011, p. 393) “as contradições da sociedade brasileira, acabou constituindo-se num espaço importante para o desenvolvimento de uma tendência crítica que, embora não predominante, gerou estudos consistentes e significativos sobre a educação.” Ao mesmo tempo que a pós-graduação foi estruturada por meio da influência americana, ela também constituiu em seu interior formas de resistência, sobreduto no setor educacional.

Assim, vários trabalhos nesta perspectiva favoreceram questionamentos ao contexto educacional, denunciando suas contradições e dimensão ideológica. Para Saviani (2004) surgiram

\footnotetext{
${ }^{22}$ Para Oliveira (1998) a metodologia reafirma a importância da reflexão capaz de abarcar os procedimentos construtivos de uma pesquisa em ciências humanas.
}

Nucleus, v.17, n.2, out. 2020 
correntes de pesquisa de tendência crítica, contribuindo com estudos contra-hegemônicos em relação a pedagogia dominante. Podemos notar que a pós-graduação também contribuiu com críticas que colocarim o modelo "associado-dependente" em declínio, sobretudo no setor educacional a partir dos anos 1980. Foi nesta década considerada "perdida" que a estrutura ditatorial do regime militar foi desmantelada, abrindo espaço para o retorno da democracia participativa com a reabertura política.

Neste contexto, a pesquisadora Bernadete Gatti (2007; 2001) levanta em discussão crítica alguns questionamentos que surgiram no meio da pesquisa educacional na década de 1980/90. As considerações sobre as questões de método, principalmente na dificuldade de construção de categorias teóricas. Destaca as dominações hegemônicas dentro das universidades e o empobrecimento teórico das pesquisas. Aborda as lacunas no seio das universidades, e a inexistente consolidação de tendências de trabalho no campo. Exemplo claro é a distância entre as pesquisas universitárias e a realidade educacional brasileira. A produção acadêmica, em descompasso temporal. O conhecimento em educação é fruto de um processo histórico lento e ineficiente para responder aos atuais anseios da sociedade. A autora defende a necessidade de investigações com consistência, foco, e abrangência, para se legitimar criticamente na prática (GATTI, 2007; 2001).

Neste mesmo sentido, Pedro Demo (2011) explicita grande preocupação com a questão do método $^{23}$, que segundo o autor, em toda investigação é sinal de competência, seriedade e bom nível. Neste sentido, é imprescindível debater a questão de método nas ciências humanas. Desenvolver ideias sobre os problemas teóricos e metodológicos. Abordar e refletir a necessidade de sedimentar a pesquisa de qualidade em educação. Debater estas questões perpassa pela compreensão da verdade transitória na ciência, a subjetividade do pesquisador perante o seu objeto de estudo e a importância da originalidade metodológica (DEMO, 2011; GATTI e ANDRÉ, 2010).

Gatti (2007) pontua a dificuldade de se construir na Educação categorias teóricas mais consistentes (e que não sejam aplicações ingênuas, utilizadas em outras áreas do conhecimento, como ocorria nos estudos educacionais de matriz teórica positivista) e abarquem a complexidade das questões em seu contexto social. Sinaliza o fato de que a natureza da pesquisa não é resolver problemas, mas fornecer aprofundamento teórico e discussão: "a busca da pergunta adequada, da questão que não tem resposta evidente, é que constitui o ponto de origem de uma investigação científica" (p. 23). A indagação que orienta o estudo é proveniente de um corpus já estabelecido.

Entretanto, falta tradição em pesquisa educacional, bem como estofo teórico que abarque um problema além de especificidades e recortes situacionais. Parte desses confrontos tem a ver com a chamada abordagem qualitativa, cujo uso se expandiu pela busca de métodos alternativos aos modelos experimentais. Conforme já explicitado, o poder explicativo do positivismo sobre os fenômenos

\footnotetext{
${ }^{23}$ Para Oliveira (1998) o método relaciona-se aos fundamentos e processos que amparam uma determinada reflexão. Ele existe para auxiliar na construção de uma representação adequada da realidade a ser estudada.
} 
educacionais vinha sendo posto em questão, como também se colocaram em dúvida os conceitos de objetividade e neutralidade (GATTI, 2010, 2007; 2001).

Os estudos empreendidos no campo educacional mostram uma teorização ainda precária e onde há, nas apropriações teórico-metodológicas de outras áreas, grandes distorções e ambiguidades. O método deve ser compreendido como forma de construção de conhecimento, como ato vivo, concreto, que se revela na organização de um determinado trabalho. Nasce do confronto de ideias, perspectivas e teorias com a prática. O conhecimento científico para Gatti $(2007 ; 2001)$ necessita ser construído com coerência, lógica sustentável e espírito crítico, se preocupando com as repercussões científicas e éticas.

A ética em pesquisa é o respeito pela dignidade humana e proteção aos participantes das mesmas, protegendo os seres humanos de possíveis danos materiais e imateriais na forma da lei. A resolução n ${ }^{\circ} 510$ de 7 de abril de 2016 é uma diretriz do Conselho Nacional da Saúde, que regulamenta a ética em pesquisa. É a primeira norma brasileira da área. Foi elaborada pelo grupo de trabalho da Comissão Nacional de Ética em Pesquisa (GT CHS/CONEP), fruto de reivindicações antigas dos membros da Comissão Nacional de Ética em Pesquisa (CONEP) das áreas de Ciências Humanas e Sociais.

Segundo esta norma, as investigações empíricas ${ }^{24}$ passariam a ser revisadas pelo sistema CEP/CONEP. A resolução anterior, 466/12, possui uma concepção positivista e inadequada para resguardar eticamente as pesquisas em Ciências Humanas e Sociais. A nova resolução (510/2016) vem colaborar para o estabelecimento de relações éticas entre pesquisadores e participantes dos estudos, conferindo validação, qualidade e humanidade nos trabalhos empíricos (MAINARDES, 2017; GUERRIERO, 2016).

Apesar dos avanços, não podemos nos eximir dos existentes problemas teórico/metodológicos do campo da pesquisa em educação.

\footnotetext{
${ }^{24}$ Segundo Mills (2009), o objetivo da investigação empírica é dirimir discordâncias e possibilitar discussões frutíferas.
} Nucleus, v.17, n.2, out. 2020 


\section{Quadro 4: Os problemas teóricos/metodológicos da pesquisa em Educação.}

\section{Problemáticas}

Falta de solidez no domínio do método e dos instrumentos de análise desenvolvidos pelo pesquisador.

Apropriações teórico-metodológicas de outras áreas com grandes distorções e ambiguidades.

Insuficiente estofo teórico que abarque um problema além de especificidades e recortes situacionais.

Dificuldade na construção de categorias teóricas.

Distância entre as pesquisas nas universidades e a realidade educacional na sociedade brasileira.

\section{Resultados}

Falta de maturação teórica

Crise na qualidade dos trabalhos

Teorizações precárias - empobrecimento teórico das pesquisas.

Categorização inconsistente.

Inapropriada interpretação da realidade social

(Baseado em Gatti (2007; 2012).

Uma pesquisa de qualidade se caracteriza pelo domínio do método e dos instrumentos de análise desenvolvidos pelo pesquisador. O método carece condizer com a epistemologia e com a teoria adotada. Para Demo (2011) o pesquisador necessita possuir senso crítico, sólido e conhecimento teórico para desenvolver trabalhos relevantes. Para Oliveira (1998) ele deve ser criterioso, imaginativo e ético; formar contrapontos, confrontar autores e ultrapassar os limites construídos pela ciência, elaborando assim, conhecimentos necessários para a interpretação e transformação da realidade social, objetivo irrevogável da pesquisa em educação. Neste sentido, entendemos ser primordial compreender as principais problemáticas e tendências apontadas nas ultimas décadas.

Gatti (2007) elabora um balanço histórico das principais questões debatidas no campo da Educação dos anos 80 aos anos 2000. Para esta análise, ela utiliza as produções científicas discutidas e publicadas na revista "Cadernos de Pesquisa" da Fundação Carlos Chagas, referência na argumentação e compreensão científica das indagações educacionais. As publicações discutem problemas e alternativas metodológicas da escrita educacional, com o apoio do Conselho Nacional de Desenvolvimento Científico e Tecnológico $(\mathrm{CNPq})$ e as tendências teóricas ao longo destas três décadas nas pesquisas. Para a autora, houve uma crise na qualidade dos trabalhos e no seu potencial impacto, bem como a falta de maturação teórica e isolamento da educação perante as ciências humanas.

Por meio deste balanço, podemos entender os limites do método quantitativo e o início das pesquisas qualitativas no Brasil. Por outro lado, identificar e compreender a relação entre a pesquisa, as políticas educacionais e o processo educacional, compreendendo e advogando as questões ligadas ao rigor metodológico, sua eficiência, subjetividade, objetivação e interdisciplinaridade. Também, problematizar as condições institucionais da pesquisa em Educação, as contribuições de diferentes metodologias e a formação de professores. Neste sentido, André (2010) aponta os avanços nos últimos 
dez anos, com a consolidação de um campo autônomo de estudos, carecendo de um maior fortalecimento. Gatti $(2007 ; 2001)$ afirma que as três décadas expostas acima contribuíram para alavancar as investigações, teoricamente e metodologicamente. Devemos sempre reconhecer que quantidade não é sinônimo de qualidade, exemplo claro é o grande volume de trabalhos publicados nas últimas décadas sem o devido rigor e consistência metodológica, pesquisas com aspectos de "porosidade" de conhecimentos e pouco impacto social (GATTI, 2007; 2001).

Destarte, como deixar de lado a discussão sobre o desenvolvimento da pesquisa em Educação no Brasil? Como não se preocupar com os desafios teóricos/metodológicos que limitam o trabalho dos pesquisadores no campo da Educação? As deficiências educacionais, as políticas educacionais e o processo de desenvolvimento educacional necessita ser indagado constantemente, buscando apropriadas reflexões para tomada de decisões ao abismo entre Pesquisa e Realidade concreta que os números do Pisa (2019), do Relatório de Desenvolvimento Humano (2019) demostram.

\section{CONSIDERAÇÕES FINAIS}

Inegavelmente as contradições sociais, econômicas e políticas continuam cooperando para avanços e retrocessos na reconstrução social pela via educacional, impossibilitando a sua real concretização. A democratização do ensino gratuito e de qualidade para todos ainda continua um desafio a ser alcançado. As políticas educacionais carecem de um maior amadurecimento e uma digna abrangência, que coloque as prioridades sociais ao patamar da valorização humana.

A dualidade do sistema educacional ampliou na última década ao invés de regredir. As políticas neoliberais e privatistas aprofundam os abismos socioeconômicos entre o rico e o pobre, ficando submetido a determinada alienação a reprodução das relações de produção. Os avanços se entrelaçam com ondas de retrocesso, contribuindo para perpetuar viva a raiz educacional brasileira, pautada nas diferenças sociais.

O Estado brasileiro demostra sinais cada vez mais claros de suas intenções privatistas, entregando o sistema educacional ao neotecnicismo, pautado em reformas empresariais de cunho mercantilista. Neste contexto, o governo atribui a si um novo papel, de fiscalizador e monitorador de metas e resultados, típicas do neoliberalismo, mantendo-se omisso em relação aos dilemas sociais mais relevantes (educação, saúde, segurança), suas medidas são superficiais para efeitos breves em curto prazo. As privatizações estão ocorrendo, escolas e universidades são compradas por grandes corporações educacionais. Ao mesmo tempo os abismos sociais estão se ampliando.

Os números do PNUD demonstram a precariedade e péssima distribuição de renda do Brasil no mundo, como o segundo pior índice. Demostra também que cada vez mais a renda e a riqueza produzida estão se concentrando nas mãos dos mais ricos, com a maior concentração de renda de todos 
do grupo de países em desenvolvimento do BRICS. A Pesquisa Nacional por Amostra de Domicílios (PNAD/IBGE) nos indicou que ainda temos 11,5 milhões de analfabetos e 7,3 milhões de crianças que não frequentam a escola.

Por conseguinte, vivemos num processo de avanço e retrocesso nos índices educacionais. Entre 2000 a 2009, avanços significativos. Por sua vez, de 2010 a 2020 regredimos no desempenho educacional, com um dos piores índices do Pisa. Neste sentido defendemos que maiores investimentos em pesquisas educacionais são imprescindíveis para responder aos desafios apresentados e superar as barreiras do estabelecido, respondendo aos anseios sociais com instrução de qualidade, distribuição de renda, erradicação do analfabetismo e melhores desempenhos educativos em nível mundial.

Mediante ao exposto, problematizar a pesquisa educacional no Brasil propiciou reflexões acerca da complexidade da ciência, a necessidade de um desenvolvimento teórico/metodológico consistente nos trabalhos acadêmicos. Indagações em relação a pesquisa educacional e seus impactos sociais. Também, pensar a importância dos conhecimentos acumulados é um importante ponto de partida para as pesquisas, visando à superação das barreiras/limites estabelecidos pelo conhecimento, de maneira responsável e ética.

$\mathrm{O}$ trabalho aqui desenvolvido não visa à desconstrução, o modismo, a defesa de pesquisas inócuas e a ondas inovadoras. Acreditamos que a pesquisa educacional qualitativa, pode apontar novos caminhos e olhares abrangentes à área, eliminando a porosidade de conhecimento que tem caracterizado as investigações. É preciso valorizar a importância da coerência, meticulosidade, complexidade, vigilância epistemológica, rigor científico e relevância social. Isso devolverá à sociedade reflexões científicas que podem fazer frente aos problemas levantados acima, buscando melhorias na qualidade da educação e consequentemente na vida social.

Em outras palavras, a pesquisa qualitativa, realizada de forma metodologicamente adequada, pode apontar caminhos para aprimorar a educação brasileira e, uma educação melhor para todos pode propiciar condições para uma sociedade mais igualitária, portanto, mais justa.

\section{REFERÊNCIAS}

ANDRÉ, Marli. Formação de professores: a constituição de um campo de estudos. Educação, v. 33, n. 3, p. 174-181, 2010.

AKKARI. Abdeljalil. Internacionalização das políticas educacionais. Rio de Janeiro: Vozes, 2011.

ALMEIDA, Jane Soares. O legado educacional do século XX. In: SAVIANI, Demerval et al. O legado educacional do século XX no Brasil. Campinas: Autores Associados, 2004.

ALVES-MAZZOTTI, Alda; GEWANDSZNAJDER, Fernando. O método nas ciências naturais e sociais: pesquisa quantitativa e qualitativa. São Paulo: Pioneira, 1998. 
AZEVEDO, Janete Maria Lins. O Estado, a política educacional e a regulação do setor educação no Brasil: uma abordagem histórica. In: FERREIRA, Naura Syria Carapeto; AGUIAR, Márcia Ângela da S. Gestão da educação: impasses, perspectivas e compromissos. In: Gestão da educação: impasses, perspectivas e compromissos. 2001. p. 318-318.

DEMO, Pedro. Pesquisa: princípio científico e educativo. 14. ed. São Paulo: Cortez, 2011.

DESLANDES, Suely Ferreira. A construção do Projeto de Pesquisa. In: DE SOUZA MINAYO, Maria Cecília; DESLANDES, Suely Ferreira; GOMES, Romeu. Pesquisa social: teoria, método e criatividade. Editora Vozes Limitada, 2004.

FREITAS, Luiz Carlos de. Os reformadores empresariais da educação: a consolidação do neotecnicismo no Brasil. Texto apresentado ao $10^{\circ}$ Encontro de pesquisa em educação da região sudeste. Rio de Janeiro, 2011.

GATTI, Bernadete; ANDRÉ, Marli. A relevância dos métodos de pesquisa qualitativa em Educação no Brasil. In: BOHNSACK, Ralf et al. Metodologias da pesquisa qualitativa em educação: teoria e prática. Petrópolis, RJ: Vozes; 2010.

GATTI, Bernadete Angelina. A construção metodológica da pesquisa em educação: desafios. Revista Brasileira de Política e Administração da Educação-Periódico científico editado pela ANPAE, v. 28, n. 1, 2012.

GATTI, Bernadete Angelina. A construção da pesquisa em Educação no Brasil. Brasília: Liber Livro, 2007.

GATTI, Bernadete Angelina. Implicações e perspectivas da pesquisa educacional no Brasil cotemporâneo. Cadernos de pesquisa, n. 113, p. 65-81, 2001.

GOODSON, Ivor. F. Processos de mudança e períodos históricos: uma perspectiva internacional. In: GOODSON, Ivor. As políticas de currículo e de escolarização. Petrópolis: Vozes, 2008. p. $59-72$.

GUERRIERO, Iara Coelho Zito. Resolução n ${ }^{\circ} 510$ de 7 de abril de 2016 que trata das especificidades éticas das pesquisas nas ciências humanas e sociais e de outras que utilizam metodologias próprias dessas áreas. Ciência \& Saúde Coletiva, v. 21, p. 2619-2629, 2016.

INSTITUTO BRASILEIRO DE GEOGRAFIA E ESTATÍSTICA - IBGE. Pesquisa Nacional por Amostra de Domicílios (Pnad) contínua trimestral. 2017. Disponível em: <http://www.ibge.gov.br/home/estatistica/indicadores/trabalhoerendimento/pnad_continua/>. Acesso em: 20 dez. 2019.

LAVILLE, Christian; DIONNE, Jean. A construção do saber. Belo Horizonte: UFMG, 1999.

MACHADO, Nilson José. Sobre a ideia de projeto. In: MACHADO, Nilson José. Educação: projetos e valores. $5^{\circ}$ ed. São Paulo: Escrituras, 2004. p. 1-37.

MAINARDES, Jefferson. A ética na pesquisa em educação: panorama e desafios pós-Resolução CNS nº 510/2016. Educação, v. 40, n. 2, p. 160-173, 2017.

MILLS, Charles Wright. Sobre o Artesanato Intelectual. In: MILLS, Charles Wright. Sobre o Artesanato Intelectual e outros ensaios. Rio de Janeiro: Zahar, 2009. 
NACARATO, Adair Mendes. A parceria universidade-escola: utopia ou possibilidade de formação continuada no âmbito das políticas públicas?. Revista Brasileira de Educação, v. 21, n. 66, p. 699-716, 2016.

NAÇÕES UNIDAS BRASIL - ONU. Relatório de desenvolvimento humano do PNUD destaca altos índices de desigualdade no Brasil. In: Programa das Nações Unidas para o

Desenvolvimento (PNUD). 2019. Disponível em: https://nacoesunidas.org/relatorio-dedesenvolvimento-humano-do-pnud-destaca-altos-indices-de-desigualdade-no-brasil/. Acesso em: 20 dez. 2019.

OLIVEIRA, Paulo de Salles. Caminhos de construção da pesquisa em Ciências Humanas. In: OLIVEIRA, Paulo de Salles (org.). Metodologia das Ciências Humanas. São Paulo: Hucitec/Unesp, 1998. p. 17-26.

ORGANIZAÇÃO PARA COOPERAÇÃO E DESENVOLVIMENTO ECONÔMICO - OCDE. Relatório Brasil no PISA (2018). In: MEC. Diretoria de Avaliação da

EducaçãoBásica(DAEB).2019. Disponível em:

http://download.inep.gov.br/acoes_internacionais/pisa/documentos/2019/relatorio_PISA_2018_pr eliminar.pdf. Acesso em: 20 dez. 2019.

SANTOS, Jair Ferreira dos. O que é pós-moderno. São Paulo: Brasiliense, 2006.

SAVIANI, Dermeval et al. O legado educacional do século XX. Autores Associados, 2004.

SAVIANI, Dermeval. História das ideias pedagógicas no Brasil. $3^{\circ}$ ed. Campinas: Autores Associados, 2011.

SEVERINO, Antônio. Metodologia do trabalho científico. 22. ed. São Paulo: Cortez, 2002.

SILVA, Kalina Vanderlei; SILVA, Maciel Henrique. Dicionário de conceitos históricos. Editora Contexto, 2005.

SHIROMA, Eneida Oto; MORAES, Maria Célia Marcondes de; EVANGELISTA, Olinda. Política educacional. 2. ed. Rio de Janeiro: DP\&A, 2002. 